\title{
Clinicopathological and Prognostic Significance of Immunoscore and PD-LI in Intrahepatic Cholangiocarcinoma
}

This article was published in the following Dove Press journal: OncoTargets and Therapy

\author{
Hong $\mathrm{Wu}^{\prime}$ \\ Yulong $\mathrm{Wei}^{2}$ \\ Mei Jian' \\ Hong Lu ${ }^{2}$ \\ Qingzhu Song ${ }^{3}$ \\ Liheng $\mathrm{Hao}^{4}$ \\ Yong Yue ${ }^{4}$ \\ 'Department of Ultrasound, Inner \\ Mongolia Bayannaoer City Hospital, \\ Bayannaoer 015000, Inner Mongolia, \\ People's Republic of China; ${ }^{2}$ Department \\ of Pathology, Inner Mongolia Bayannaoer \\ City Hospital, Bayannaoer 015000, Inner \\ Mongolia, People's Republic of China; \\ ${ }^{3}$ Department of Clinical Laboratory, \\ Inner Mongolia Bayannaoer City Hospital, \\ Bayannaoer 0I5000, Inner Mongolia, \\ People's Republic of China; ${ }^{4}$ Department \\ of Hepatobiliary Surgery, Inner Mongolia \\ Bayannaoer City Hospital, Bayannaoer \\ 015000, Inner Mongolia, People's \\ Republic of China
}

Background: An increasing amount of evidence reveals that immunosuppression is a major issue in cancer progression. The association of immunoscore (IS) and its impact on clinical outcome have been studied in many tumor types, but its significance in intrahepatic cholangiocarcinoma (ICC) is poorly known.

Methods: By immunohistochemistry, CD3 and CD8 expressions were assessed in tissue samples of 50 cases of postoperative ICC. The IS was determined by analyzing CD3+ and CD8+ expression data in different areas (intratumor and invasion margins). The relationship between IS and clinicopathological characteristics, including the overall survival (OS) and recurrence-free survival (RFS), was analyzed. In addition, PD-L1, a major regulator of immune escape, was also assessed in tumor cells by immunohistochemistry.

Results: IS was related to histological differentiation $(\mathrm{P}=0.026)$, the presence of lymphoid metastasis $(\mathrm{P}=0.034)$, and TNM clinical stages $(\mathrm{P}=0.031)$ of ICC. High IS was significantly associated with better RFS $(\mathrm{P}=0.033)$ and $\operatorname{OS}(\mathrm{P}=0.014)$. IS was an independent prognostic factor for better OS in multivariate analysis. PD-L1 expression was closely related to tumor vascular invasion $(P=0.044)$. Although there was no association between PD-L1 expression and IS, high PD-L1 expression in tumor cells indicated poor RFS $(\mathrm{P}=0.017)$ and $\mathrm{OS}$ $(\mathrm{P}=0.004)$ in ICC.

Conclusion: The IS and PD-L1 may be used as a complement to the TNM system for predicting the prognosis of patients with ICC.

Keywords: intrahepatic cholangiocarcinoma, microenvironment, immunoscore, PDL1, prognosis

\section{Introduction}

Cholangiocarcinoma is a heterogeneous group of epithelial cell malignancies including intrahepatic, perihilar, and distal tumors according to the anatomical location within the biliary tree. Intrahepatic cholangiocarcinoma (ICC) is the second most common primary liver malignancy. ${ }^{1}$ ICC incidence is increasing worldwide. $^{2}$ It can be attributed to hepatitis virus, hepatolithiasis, and hepatobiliary flukes. The overall prognosis for patients with ICC is dismal with a 5-year survival rate of $14 \%-40 \%$ after surgical resection. ${ }^{3}$ Many patients who received curative treatment for ICC eventually experienced relapse. New effective adjuvant treatment strategies are in great demand.

Conventionally, the tumor size/regional lymph node involvement/distant metastasis (TNM) classification system is used to describe tumor burden and assess the
Correspondence: Yong Yue Department of Hepatobiliary Surgery, Inner Mongolia Bayannaoer City Hospital, Bayannaoer 015000, Inner Mongolia, People's Republic of China

Tel +8618504789505

Fax +86 04788415386

Email nmgbsyycs@126.com
OncoTargets and Therapy 2021:14 39-5I

submit your manuscript DovePress $\boldsymbol{f}$ in $\boldsymbol{\nabla}$

http://doi.org/10.214710TT,S288982 
prognosis in solid tumors. Based on clinicopathological features, TNM staging system could not provide information on tumor biological behavior. Tumor microenvironment comprises a network of cells including fibroblasts, immune cells, and endothelial cells. An increasing amount of evidence indicated that the type, density, functional orientation, and location of immune cells within distinct tumor regions may strongly influence the evolution of various cancers and may provide prognostic information. ${ }^{4,5}$ Based on the density and location of CD3positive and CD8-positive cells, Galon et al developed an immunoscors (IS) system that shows useful prognostic value for colorectal cancer, pancreatic cancer, and hepatocellular carcinoma. ${ }^{6-9}$ Some studies have shown that the IS gives even better prognostic accuracy than the standard TNM system. ${ }^{6-10}$ Although IS has been identified as a potential prognostic index for some gastrointestinal cancers, the prognostic role of IS remains largely undetermined for ICC.

Programmed death ligand 1 (PD-L1), a member of the B7 family, could bind to the $T$ cell surface receptor programmed death 1 (PD-1). PD-1 activation by PD-L1 can inhibit the proliferation and survival of cytotoxic T lymphocytes. ${ }^{11}$ By overexpressing PD-L1, tumor cells escape immune surveillance. Emerging clinical data have shown that the upregulation of PD-L1 in multiple tumor types has prognostic implication and can predict the clinical response to PD-1 blockade therapy. ${ }^{12,13}$ Although the potential clinical relevance of PD-L1 expression in ICC has already been reported in several previous studies, the prognostic value of PD-L1 for ICC is still controversial. $^{14-17}$

This study aimed to examine the clinicopathological and prognostic roles of T-lymphocyte-based IS, following similar principles described by Galon et al in ICC. ${ }^{8}$ The clinical impact of PD-L1 expression in ICC and the relationship between IS and PD-L1 were also investigated.

\section{Patients and Methods}

\section{Patients}

This study was approved by the institutional review board of Bayannaoer City Hospital and was conducted in accordance with the standards of the Declaration of Helsinki. A total of 50 patients were included in the current study. The primary ICC tissue samples were obtained from ICC patients who underwent surgical resection between January 2013 and June 2020. All participants have signed written informed consent. None of the patients had received any chemotherapy or radiotherapy before their operation. The pathological diagnosis of all cases was independently confirmed by two experienced pathologists by observing the hematoxylin and eosin (H\&E) sections. Tumor stage was determined according to the American Joint Committee on Cancer (AJCC)/Union for International Cancer Control TNM classification system. The clinicopathological information was obtained from patients' clinical records and pathological reports.

Data were censored at the last follow-up for patients without recurrence or death. OS and recurrence-free survival (RFS) were defined as the interval between the date of surgery to the date of death or recurrence.

\section{Immunohistochemistry and Immunoscore Determination}

Three-micrometer-thick pathologic sections from paraffin blocks were stained with antibodies to CD3 (Zhongshan Chemical Co., Beijing, China), CD8 (Zhongshan Chemical Co., Beijing, China) and PD-L1 (Abcam, Cambridge, UK). The immunohistochemistry was performed in accordance with the two-step protocol according to the manufacturer's instructions.

Slides stained for CD3+, CD8+ and PD-L1+ cells were first evaluated by a clinical pathologist. The tumor interior (TI) and invasive margin (IM) were marked for biomarker imaging. The invasive margin was defined as a region of $0.5 \mathrm{~mm}$ on each side of the border between tumor cells and normal liver tissue. Under high power magnification $(20 \times)$, images were captured in areas where immune cell infiltrate density was focally high with an Olympus digital camera. For both CD3+- and CD8+-stained slides, three most representative fields were selected and photographed in the TI and IM areas, respectively. The numbers CD3-positive or CD8-positive staining cells were counted automatically by using Imagepro plus 6.0 software. The median immune cell density was used to stratify patients into "high" or "low" cell density groups. The cutoff values were as follows: 162 for CD3+ TI, 497 for CD3+ IM, 92 for CD8+ TI, and 305 for CD8+ IM. The "high" and "low" groups were used to form the immunoscore. Patients with low densities of CD3+ and CD8+ T cells in both TI and IM tumor regions were classified as IS0; patients with one high density for one marker were classified as IS1; patients with two, three and four high densities for the two markers were classified as IS2, IS3, and IS4, respectively (supplemental table). Due to limited 
number of ICC patients, we included IS0 and IS1 groups to one group (low IS group), IS2 formed moderate IS group, and IS3-4 the high IS group.

\section{Statistical Analysis}

Demographic, clinical and tumor characteristics are presented as percentages or median values. The statistical analysis was performed with SPSS 16.0 statistical software. Comparison of categorical variables was performed using the chi-squared test. The Kaplan-Meier method was used to calculate RFS and OS. Survival data were analyzed with the Log rank test. Univariate and multivariate Cox proportional hazard regression model was used to calculate hazard ratios for OS and RFS. All statistical tests were two-sided. A difference was considered significant for $P<0.05$.

\section{Results}

\section{Clinicopathologic Characteristics of Patients}

The study population included 50 tumor samples collected from patients who underwent surgery for the management of ICC. The patients included 25 men and 25 women with a mean age of 60 years (range 35-77 years). Eight out of the 50 patients presented with multiple lesions. Regarding etiology of HCC, 14\% $(n=7)$ of patients had viral hepatitis $\mathrm{B}(\mathrm{HBV}), 2 \%(\mathrm{n}=1)$ patients had viral hepatitis $\mathrm{C}(\mathrm{HCV}), 18 \%(\mathrm{n}=9)$ of patients had cholelithiasis. The median levels of CEA, CA19-9 were $11.5 \mu \mathrm{g} / \mathrm{L}$ and 640U/ $\mathrm{mL}$, respectively, respectively. The median tumor size was $4.7 \mathrm{~cm}$ (range 1-12cm). Histologic evaluation found most tumors to be moderately differentiated $(n=34,68 \%)$, with vascular invasion noted in 6 tumor samples (12\%), perineural invasion in 9 tissue samples (18\%). Lymph node metastases were found in $24 \%(n=12)$ of the patients. Of the 50 ICC samples, 25 were stage I, 9 were stage II, 16 were stage III according to the AJCC staging system.

\section{Relationship of Immunoscore (IS) with Clinicopathologic Features of ICCs}

The staining of CD3+ and CD8+ cells in the ICC tissue sections demonstrated that the lymphocyte densities differed significantly between the tumor interior and invasive margin regions. The average number of $\mathrm{CD} 3+, \mathrm{CD} 8+$ $\mathrm{T}$ cells in the invasive margin regions was significantly higher than those of in the tumor interior regions $(\mathrm{P}=0.047, \mathrm{P}=0.009$, respectively) (Figure 1). The IS distribution of the study population was as follows: IS0-1 $60.0 \%(\mathrm{n}=30)$, IS2 $16.0 \%(\mathrm{n}=8)$, and IS3-4 24.0\% $(\mathrm{n}=$ 12). The clinical and pathological features of all 50 ICC cases were analyzed. IS was correlated with histological differentiation $(\mathrm{P}=0.026)$, the presence of lymphoid metastasis $(\mathrm{P}=0.034)$ and TNM clinical stages $(\mathrm{P}=0.031)$ of ICC. The IS of ICC was significantly higher in well and moderately differentiated cases than in poorly differentiated ones. IS was found to lower in samples with higher clinical stages and metastasis/recurrence. No association with other clinicopathological variables and IS was observed (Table 1).

\section{The Prognostic Implications of is in ICCs}

The study was censored on August 12, 2020. The median follow-up time was 26.5 months (range 7-71 months). The median overall survival was 25.8 months (range, 1-71 months). During the follow-up period, $50 \%$ of all patients $(\mathrm{n}=25)$ developed recurrence and $24 \%(\mathrm{n}=12)$ died. Median OS for low (0-1), moderate (2), and high (3-4) IS was 23.0, 25.0 and 33.8 months, respectively. Median RFS for low, moderate, and high IS groups was 11.7, 12.5 and 17.4 months, respectively. OS and RFS were illustrated by Kaplan-Meier curves (Figure 2). We found the OS and RFS of patients were gradually prolonged if correspondent IS increased: Patients in I4 group had the longest survival time. Statistical analysis showed that IS was significantly correlated with OS and RFS $(\mathrm{P}=0.014$ and 0.033 , respectively). When assessing the impact of each IS component on prognosis, we found that higher number of CD8+ cells in invasive margin and tumor interior showed a significant association with prolonged OS and RFS as well (Figure 3). Both univariate and multivariate Cox proportional hazards regression models were used to analyze the relationship between survival, clinicopathological variables, and IS. The multivariate analysis revealed that high IS was independent prognostic factors of improved OS (Table 2).

\section{The Clinicopathological and Prognostic Significance of PD-LI Expression in ICCs} PD-L1 expression was assessed by IHC analysis and PDL1 positivity was defined as $\geq 5 \%$ of the cancer cells staining positive. PDL-1 was also observed expressing on some stroma cells including regulatory $\mathrm{T}$ cells, neutrophils and macrophages. PD-L1 expression occurred in a membranous pattern on cancer cells with variable degrees of staining intensity in the cytoplasm (Figure 4). 
A

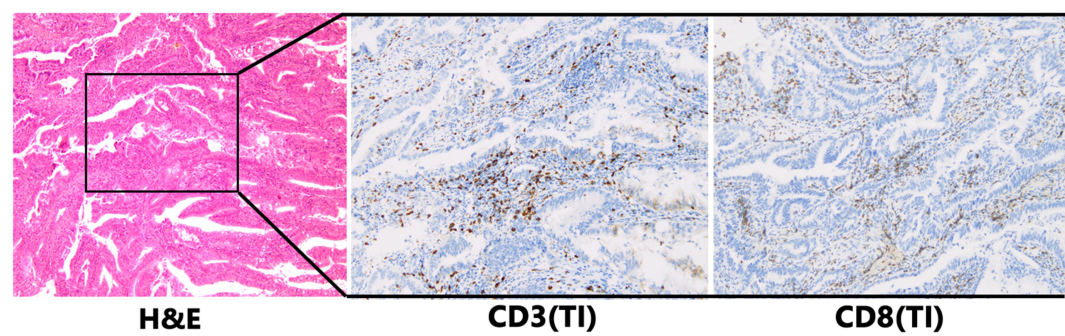

B
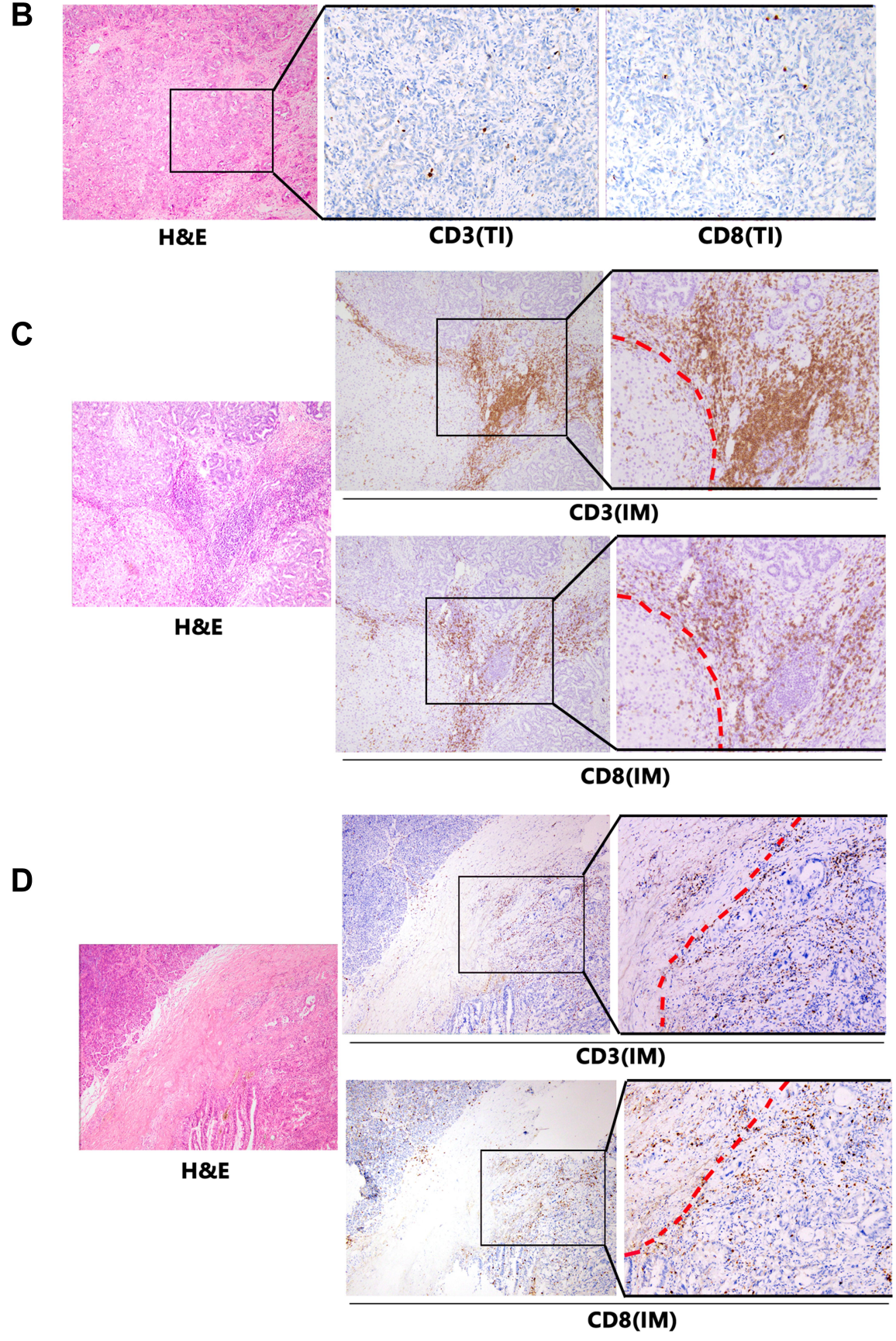

Figure I Expression of CD3 and CD8 by immune cells that infiltrated tumor interior (TI) and invasive margin (IM) of intrahepatic cholangiocarcinoma (ICC) patients. Representative images of H\&E, CD3 and CD8 staining in ICC samples are shown at $\times 100$ original magnification. The red dotted line indicates the invasive margin. (A) High CD3- and CD8-expressing cells infiltrated in TI. (B) Low CD3- and CD8-expressing cells infiltrated in TI. (C) High CD3- and CD8-expressing cells infiltrated in IM. (D) Low CD3- and CD8-expressing cells infiltrated in IM. 
Table I Clinicopathological Variables and Their Association with Immunoscore (IS)

\begin{tabular}{|c|c|c|c|c|c|}
\hline Patient Demographics & $\begin{array}{l}\text { ISO-I } \\
\text { n (\% of Row Total) }\end{array}$ & $\begin{array}{l}\text { IS2 } \\
\text { n (\% of Row Total) }\end{array}$ & $\begin{array}{l}\text { IS3-4 } \\
\text { n (\% of Row Total) }\end{array}$ & Total(\%) & P Value \\
\hline Total, n(\%) & $30(60)$ & $8(16)$ & $12(24)$ & $50(100.0)$ & \\
\hline \multicolumn{5}{|l|}{ Age groups (years) } & \multirow[t]{3}{*}{0.620} \\
\hline$<60$ & $13(54.2)$ & $5(20.8)$ & $6(25.0)$ & $24(48.0)$ & \\
\hline$\geq 60$ & $17(65.4)$ & $3(11.5)$ & $6(23.1)$ & $26(52.0)$ & \\
\hline \multicolumn{6}{|l|}{ Gender } \\
\hline Male & $15(60.0)$ & $4(16.0)$ & $6(24.0)$ & $25(50.0)$ & \multirow[t]{2}{*}{1.000} \\
\hline Female & $15(60.0)$ & $4(16.0)$ & $6(24.0)$ & $25(50.0)$ & \\
\hline \multicolumn{6}{|l|}{ Tumor nodularities } \\
\hline Single & $24(57.1)$ & $6(14.3)$ & $12(28.6)$ & $42(84.0)$ & \multirow[t]{2}{*}{0.210} \\
\hline Multiple & $6(75.0)$ & $2(25.0)$ & $0(0.0)$ & $8(16.0)$ & \\
\hline \multicolumn{6}{|l|}{ Hepatitis } \\
\hline Negative & $25(59.5)$ & $7(16.7)$ & $10(23.8)$ & $42(84.0)$ & \multirow[t]{2}{*}{0.958} \\
\hline Positive & $5(62.5)$ & $\mathrm{I}(12.5)$ & $2(25.0)$ & $8(16.0)$ & \\
\hline Cholelithiasis (yes) & $6(66.7)$ & $\mathrm{I}(\mathrm{II} . \mathrm{I})$ & $2(22.2)$ & $9(18.0)$ & 0.878 \\
\hline CEA (>5 $\mu \mathrm{g} / \mathrm{L})$ & $9(81.8)$ & I (9.1) & I (9.1) & II (22.0) & $0.24 I$ \\
\hline CA I9-9 (>37 U/mL) & I7 (54.8) & $6(19.4)$ & $8(25.8)$ & $31(62.0)$ & 0.592 \\
\hline \multicolumn{6}{|l|}{ Tumor diameter $(\mathrm{cm})$} \\
\hline$<5$ & $19(61.3)$ & $3(9.7)$ & $9(29.0)$ & $31(62.0)$ & \multirow[t]{2}{*}{0.232} \\
\hline$\geq 5$ & II (57.9) & $5(26.3)$ & $3(15.8)$ & $19(38.0)$ & \\
\hline \multicolumn{6}{|l|}{ Differentiation } \\
\hline Well & $0(0.0)$ & $0(0.0)$ & $2(100.0)$ & $2(4.0)$ & \multirow[t]{3}{*}{$0.026^{*}$} \\
\hline Moderately & $18(52.9)$ & $7(20.6)$ & $9(26.5)$ & $34(68.0)$ & \\
\hline Poorly & $12(85.8)$ & I (7.I) & I (7.I) & $14(28.0)$ & \\
\hline Perineural invasion (yes) & $6(66.7)$ & $0(0.0)$ & $3(33.3)$ & $9(18.0)$ & 0.327 \\
\hline Vascular invasion (yes) & $4(66.7)$ & I (I6.7) & I (I6.7) & $6(12.0)$ & 0.902 \\
\hline Lymphoid metastasis (yes) & II (9I.7) & $0(0.0)$ & I (8.3) & $12(24.0)$ & $0.034 *$ \\
\hline \multicolumn{6}{|l|}{ Clinical stage } \\
\hline TNM I/II & I5 (46.9) & $6(18.8)$ & II (34.4) & $32(64.0)$ & \multirow[t]{2}{*}{$0.03 I^{*}$} \\
\hline TNMIII/IV & $15(83.3)$ & $2(I I . I)$ & I (5.6) & $18(36.0)$ & \\
\hline
\end{tabular}

Note: $* P<0.05$.

Abbreviations: CEA, carcinoembryonic antigen; CA19-9, carbohydrate antigen 19-9.

Among the 50 cases, $16.0 \%$ of ICC samples $(n=8)$ scored positive for PD-L1, 24.0\% ( $\mathrm{n}=12)$ showed positive PD-L1 expression in stroma cells. We analyzed the association between PD-L1 expression and clinicopathologic parameters of ICC patients (Table 3). Tumor PD-L1 expression was significantly associated with vascular invasion $(\mathrm{P}=0.044)$. There was no significant association between PD-L1 expression and CD3+ cells in invasive 

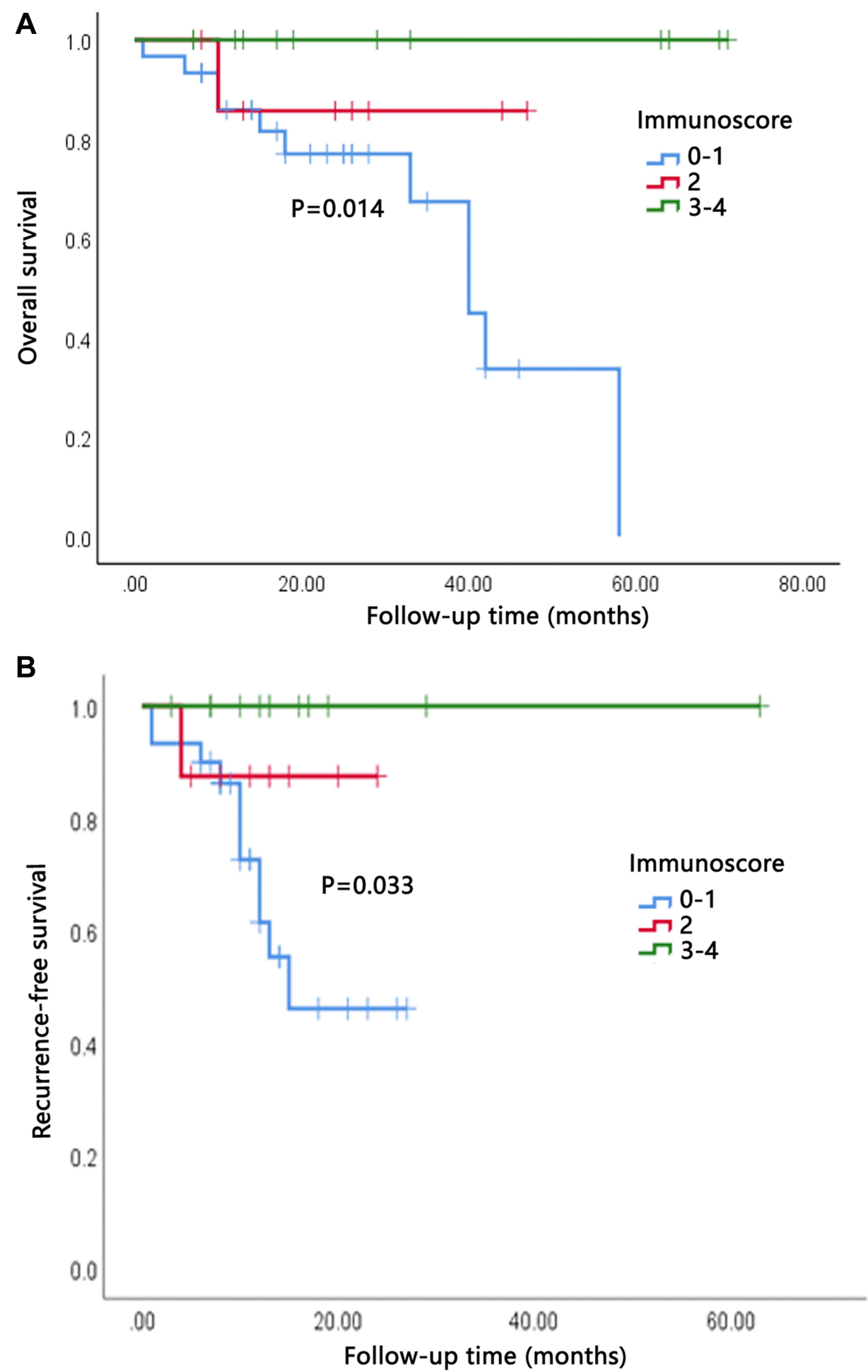

Figure 2 High immunoscore (IS) indicated better overall survival (OS) and recurrence-free survival (RFS). (A) OS of patients grouped by IS. (B) RFS of patients grouped by IS.

margin $(\mathrm{P}=0.804), \mathrm{CD} 3+$ cells in tumor interior $(\mathrm{P}=0.178)$, $\mathrm{CD} 8+$ cells in invasive margin $(\mathrm{P}=0.820)$, and $\mathrm{CD} 8+$ cells in tumor interior $(\mathrm{P}=0.614)$. No significant association was observed between PD-L1 expression and IS $(\mathrm{P}=0.958)$.
Survival analysis suggested that RFS and OS were significantly improved for patients with negative PD-L1 expression compared to those with positive PD-L1 expression $(\mathrm{P}=0.017$ and $\mathrm{P}=0.004$, respectively) (Figure 5). 

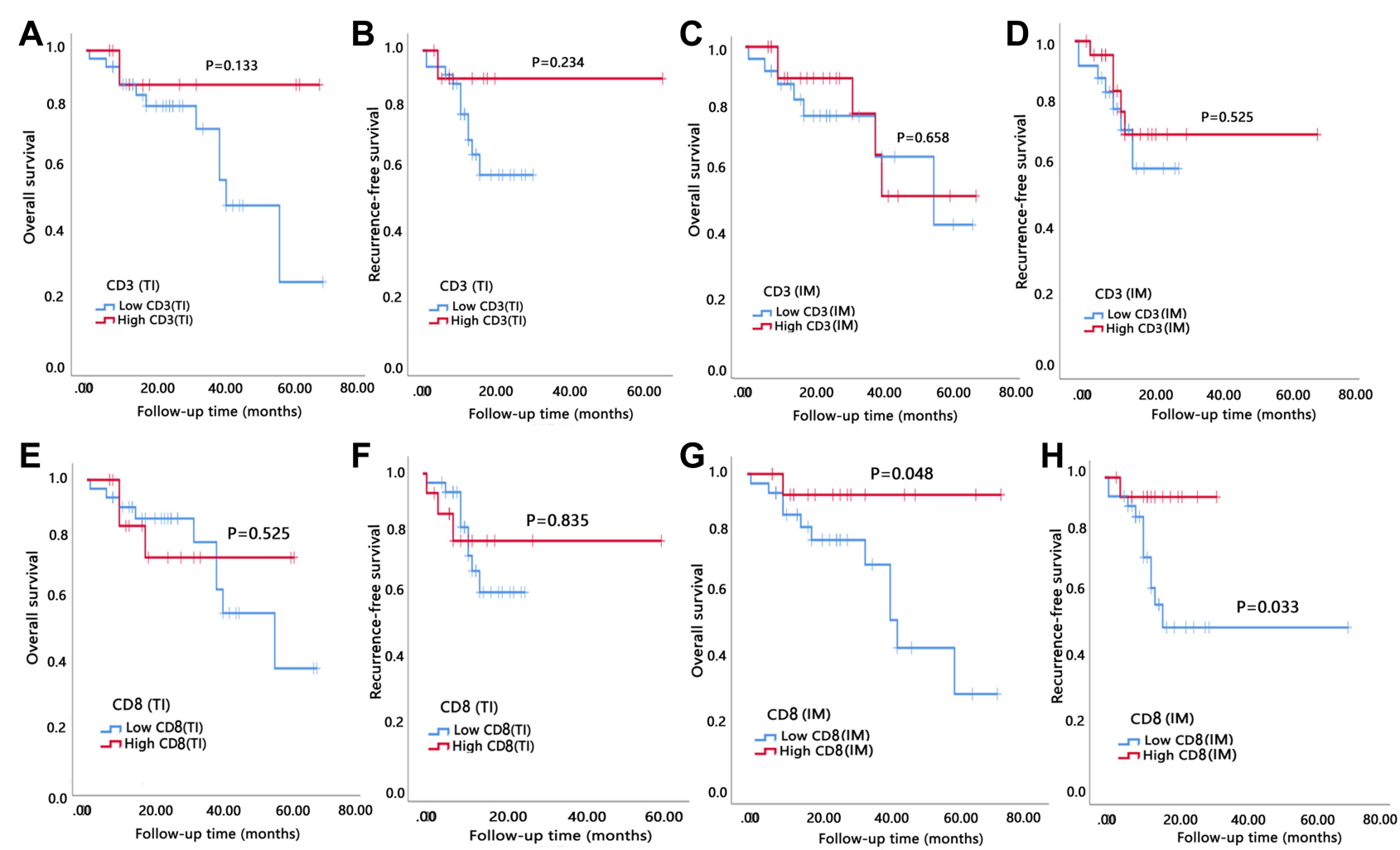

Figure 3 High degree of CD8 expression cell infiltration in the invasive margin (IM) was significantly correlated with better prognosis. (A and B) OS and RFS of patients grouped by expression of CD3 in tumor interior (TI). (C and D) OS and RFS of patients grouped by expression of CD3 in invasive margin (IM). (E and F) OS and RFS of patients grouped by expression of CD8 in tumor interior (TI). (G and $\mathbf{H})$ OS and RFS of patients grouped by expression of CD8 in tumor interior (IM).

\section{Discussion}

ICC outcomes remain unsatisfactory, even after curative resections. Aside from gemcitabine and cisplatin, no other classical chemotherapy and molecular-targeted therapy has been effective. Most patients who receive curative treatment for ICC eventually experience relapse and die from this disease. The prognosis evaluation after liver resection is of great importance for ICC.

Many researchers have aimed to define more comprehensive and precise prognostic parameters. The tumor immune microenvironment could effectively predict individualized prognosis in various tumor types, and the immune-modulating therapy options may hold promise in the therapy of tumor. To improve the utility of prognostic immune parameters, the IS concept was established in a pioneering study by Galon et al. ${ }^{8}$ IS showed encouraging performance in the prediction of the postoperative outcome of stage I-III colorectal cancer patients after surgery. ${ }^{6,8}$ Afterward, the correlation of a high IS and favorable prognosis was also demonstrated in other tumor types, including breast cancer, prostate cancer, gastric cancer, and hepatocellular carcinoma, thereby supporting the notion that high IS is a valuable prognostic marker. ${ }^{7,9,18,19}$ As in CRC, no consensus exists on the immune response measurement in ICC at present.

In this study, we counted the number of $\mathrm{CD} 3+$ and $\mathrm{CD} 8+$ cells in the most representative areas of the tumor core and invasion margin to form the IS for ICC according to the IS principle. ${ }^{20,21}$ The CD3+ and CD8+ lymphocyte populations have the best documented impact on survival and are sufficiently simple for clinical utilization. To our knowledge, this is the first time that the IS scoring system was used in ICC. The low IS was associated with poor histological differentiation, the presence of lymphoid metastasis, and high TNM clinical stages of ICC, thereby supporting the hypothesis that immune escape might increase the invasiveness of the ICC tumor. High IS was significantly associated with better overall survival (OS) and recurrence-free survival (RFS). IS was also shown to be an independent prognostic factor for better OS in the multivariate analysis, indicating that IS could be a necessary complement to TNM staging in a tumor setting other than that of colorectal cancer. In particular, we 
Table 2 Univariate and Multivariate Analysis for Overall Survival in ICC Patients

\begin{tabular}{|c|c|c|c|c|c|}
\hline & $\begin{array}{l}\text { Univariate } \\
\text { Analysis } \\
\mathbf{P} \text { value }\end{array}$ & $\begin{array}{l}\text { Overall Survival HR } \\
(95 \% \mathrm{Cl})\end{array}$ & $P$ Value & $\begin{array}{l}\text { Recurrence-Free Survival HR } \\
(95 \% \mathrm{Cl})\end{array}$ & $P$ Value \\
\hline \multicolumn{6}{|c|}{ Age (years) } \\
\hline$<60$ & \multirow[t]{2}{*}{0.082} & 1 & \multirow[t]{2}{*}{0.726} & I & \multirow[t]{2}{*}{0.496} \\
\hline$\geq 60$ & & $3.255(0.756-14.008)$ & & I.66I (0.385-7.I77) & \\
\hline \multicolumn{6}{|l|}{ Gender } \\
\hline Male & \multirow[t]{2}{*}{0.942} & 1 & & 1 & \\
\hline Female & & & & & \\
\hline \multicolumn{6}{|c|}{ Hepatitis } \\
\hline Negative & \multirow[t]{2}{*}{0.350} & 1 & & 1 & \\
\hline Positive & & & & & \\
\hline \multicolumn{6}{|c|}{ Cholelithiasis } \\
\hline Present & \multirow[t]{2}{*}{0.445} & 1 & & 1 & \\
\hline Absent & & & & & \\
\hline \multicolumn{6}{|c|}{ CAI9-9 (U/mL) } \\
\hline$>37$ & \multirow[t]{2}{*}{0.278} & I & & 1 & \\
\hline$\leq 37$ & & & & & \\
\hline \multicolumn{6}{|c|}{ Tumor diameter $(\mathrm{cm})$} \\
\hline$<5$ & \multirow[t]{2}{*}{0.073} & I & \multirow[t]{2}{*}{0.674} & 1 & \multirow[t]{2}{*}{0.601} \\
\hline$\geq 5$ & & $1.33 \mid(0.352-5.033)$ & & $0.676(0.156-2.933)$ & \\
\hline \multicolumn{6}{|c|}{ Differentiation } \\
\hline Well & \multirow[t]{3}{*}{0.268} & 1 & & 1 & \\
\hline Moderate & & & & & \\
\hline Poorly & & & & & \\
\hline \multicolumn{6}{|c|}{ Perineural invasion } \\
\hline Present & \multirow[t]{2}{*}{0.101} & 1 & & 1 & \\
\hline Absent & & & & & \\
\hline \multicolumn{6}{|c|}{ Vascular invasion } \\
\hline Present & \multirow[t]{2}{*}{$0.006 *$} & 1 & \multirow[t]{2}{*}{0.726} & 1 & \multirow[t]{2}{*}{0.466} \\
\hline Absent & & $0.735(0.132-4.102)$ & & $0.546(0.107-2.782)$ & \\
\hline \multicolumn{6}{|c|}{ Lymphoid metastasis } \\
\hline Present & \multirow[t]{2}{*}{$0.040 *$} & 1 & \multirow[t]{2}{*}{0.436} & 1 & \multirow[t]{2}{*}{0.929} \\
\hline Absent & & $0.457(0.064-3.28 I)$ & & $0.911(0.117-7.074)$ & \\
\hline
\end{tabular}


Table 2 (Continued).

\begin{tabular}{|c|c|c|c|c|c|}
\hline & $\begin{array}{l}\text { Univariate } \\
\text { Analysis } \\
\mathbf{P} \text { value }\end{array}$ & $\begin{array}{l}\text { Overall Survival HR } \\
(95 \% \mathrm{Cl})\end{array}$ & $P$ Value & $\begin{array}{l}\text { Recurrence-Free Survival HR } \\
(95 \% \mathrm{Cl})\end{array}$ & $P$ Value \\
\hline \multicolumn{6}{|c|}{ Clinical stage } \\
\hline TNM I/II & \multirow[t]{2}{*}{$0.003^{*}$} & 1 & \multirow[t]{2}{*}{0.548} & I & \multirow[t]{2}{*}{0.723} \\
\hline TNM III & & $0.695(0.212-2.280)$ & & $1.231(0.390-3.883)$ & \\
\hline \multicolumn{6}{|c|}{ Immunoscore (IS) } \\
\hline ISO-I & \multirow[t]{3}{*}{$0.033 *$} & 1 & \multirow[t]{3}{*}{$0.048 *$} & 1 & \multirow[t]{3}{*}{0.105} \\
\hline IS2 & & \multirow[t]{2}{*}{$0.176(0.031-0.981)$} & & \multirow[t]{2}{*}{$0.248(0.046-\mid .34 I)$} & \\
\hline IS3-4 & & & & & \\
\hline
\end{tabular}

Note: $* P<0.05$.

Abbreviations: CEA, carcinoembryonic antigen; CA19-9, carbohydrate antigen 19-9.

observed that a high degree of CD8 +T-cell infiltration in the invasive margin was significantly correlated with better prognosis. This finding confirmed the data of a previous study by Asahi and colleagues, who showed that $\mathrm{CD} 8+\mathrm{T}$ cell number in the outer border area was a prognostic factor for ICC, thereby suggesting that the tumor-specific T-cell immune responses could play a role in ICC progression. ${ }^{5}$ Different relationships between distribution and prognosis have been reported in different cancers. $^{22-24}$ It is unclear why only the CD8+ T cell number in the invasive margin was a prognostic factor for ICC. We speculated that it might be due to the intratumor heterogeneity of ICC. Meng and his collages have detected 16 immune markers in the tissue microarray of 168 patients with ICC who underwent liver resection. They identified four types of immune cells (CD3, CD45RA, CD57, and PD-L1) in adjacent non-tumor tissues, and one (CD66b) in neoplastic tissues, and derived

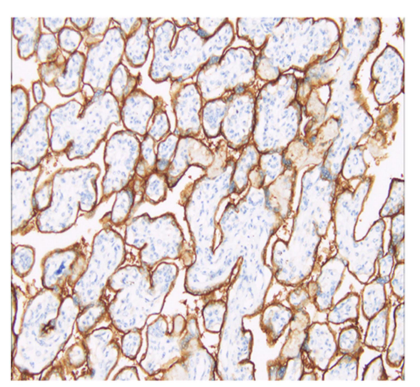

PD-L1 positive control

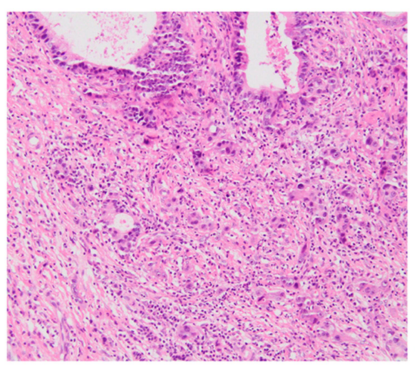

H\&E

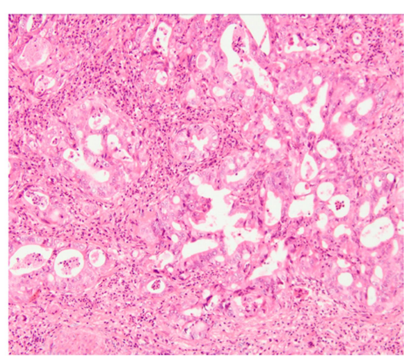

H\&E

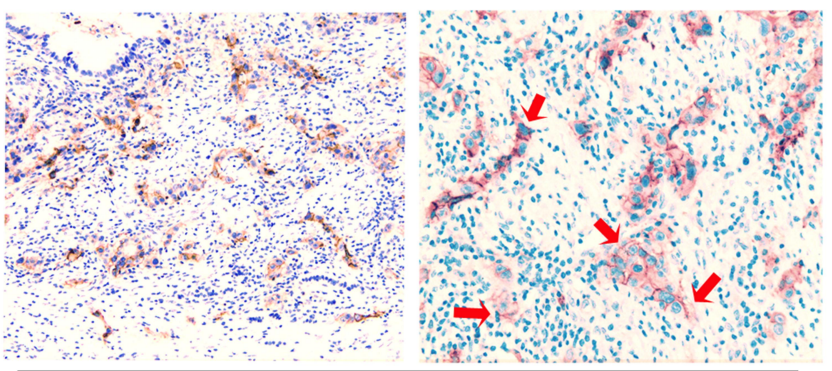

Positive PD-L1

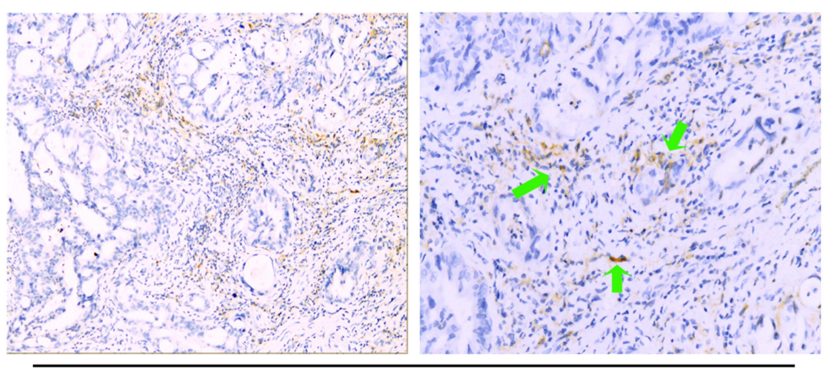

Negative PD-L1

Figure 4 Examples of PD-LI staining in representative intrahepatic cholangiocarcinoma (ICC) samples. Representative images of H\&E and PD-LI staining in ICC samples are shown at $\times 100$ original magnification. Placental tissues were used as positive control tissues for PD-LI staining. Tumor cells show membranous positivity (red arrows). In the second row, some stromal inflammatory cells show membranous PD-LI expression (green arrows), while tumor cells are negative. 
Table 3 Clinicopathological Variables and Their Association with PD-LI Expression of ICCs

\begin{tabular}{|c|c|c|c|c|}
\hline Patient Demographics & $\begin{array}{l}\text { PD-LI Positive } \\
\text { n(\% of Row Total) }\end{array}$ & $\begin{array}{l}\text { PD-LI Negative } \\
\text { n(\% of Row Total) }\end{array}$ & Total (\%) & $P$ Value \\
\hline Total, n(\%) & $30(60)$ & $8(16)$ & $12(24)$ & \\
\hline \multicolumn{5}{|l|}{ Age groups (years) } \\
\hline$<60$ & $19(79.2)$ & $5(20.8)$ & $24(48.0)$ & \multirow[t]{2}{*}{0.305} \\
\hline$\geq 60$ & $23(65.4)$ & $3(11.5)$ & $26(52.0)$ & \\
\hline \multicolumn{5}{|l|}{ Gender } \\
\hline Male & $23(92.0)$ & $2(8.0)$ & $25(50.0)$ & \multirow[t]{2}{*}{0.123} \\
\hline Female & $19(76.0)$ & $6(24.0)$ & $25(50.0)$ & \\
\hline \multicolumn{5}{|l|}{ Tumor nodularities } \\
\hline Single & $35(83.3)$ & $7(16.7)$ & $42(84.0)$ & \multirow[t]{2}{*}{0.210} \\
\hline Multiple & $7(87.5)$ & $\mathrm{I}(\mathrm{I} 2.5)$ & $8(16.0)$ & \\
\hline \multicolumn{5}{|l|}{ Hepatitis } \\
\hline Negative & $36(85.7)$ & $6(14.3)$ & $42(84.0)$ & \multirow[t]{2}{*}{0.378} \\
\hline Positive & $6(75.0)$ & $2(25.0)$ & $8(16.0)$ & \\
\hline Cholelithiasis, yes & $8(88.9)$ & $\mathrm{I}(\mathrm{II} . \mathrm{I})$ & $9(18.0)$ & 0.555 \\
\hline CEA (>5 $\mu g / L)$ & $9(81.8)$ & $2(18.2)$ & II (22.0) & 0.570 \\
\hline CAI9-9 (>37U/mL) & $26(83.9)$ & $5(16.1)$ & $31(62.0)$ & 0.649 \\
\hline \multicolumn{5}{|l|}{ Tumor diameter $(\mathrm{cm})$} \\
\hline$<5$ & $26(83.9)$ & $5(16.1)$ & $31(62.0)$ & \multirow[t]{2}{*}{0.649} \\
\hline$\geq 5$ & $16(84.2)$ & $3(15.8)$ & $19(38.0)$ & \\
\hline \multicolumn{5}{|l|}{ Differentiation } \\
\hline Well & $2(100.0)$ & $0(0.0)$ & $2(4.0)$ & \multirow[t]{3}{*}{0.694} \\
\hline Moderately & $29(85.3)$ & $5(14.7)$ & $34(68.0)$ & \\
\hline Poorly & II (78.6) & $3(21.4)$ & $14(28.0)$ & \\
\hline Perineural invasion, yes & $8(88.8)$ & I (II.I) & $9(18.0)$ & 0.555 \\
\hline Vascular invasion, yes & $3(50.0)$ & $3(50.0)$ & $6(12.0)$ & $0.044^{*}$ \\
\hline Lymphoid metastasis, yes & $9(75.0)$ & $3(25.0)$ & $12(24.0)$ & 0.287 \\
\hline \multicolumn{5}{|l|}{ Clinical stage } \\
\hline TNM I/II & $29(90.6)$ & $3(9.4)$ & $32(64.0)$ & \multirow[t]{2}{*}{0.098} \\
\hline TNMIII/IV & $13(72.2)$ & $5(27.8)$ & $18(36.0)$ & \\
\hline \multicolumn{5}{|l|}{ Immunoscore (IS) } \\
\hline ISO-I & $5(16.7)$ & $25(83.3)$ & $30(60.0)$ & \multirow[t]{3}{*}{0.958} \\
\hline IS2 & $I(12,5)$ & $7(87.5)$ & $8(16.0)$ & \\
\hline IS3-4 & $2(16.7)$ & $10(83.3)$ & $12(24.0)$ & \\
\hline
\end{tabular}

Note: $* P<0.05$.

Abbreviations: CEA, carcinoembryonic antigen; CA19-9, carbohydrate antigen 19-9. 


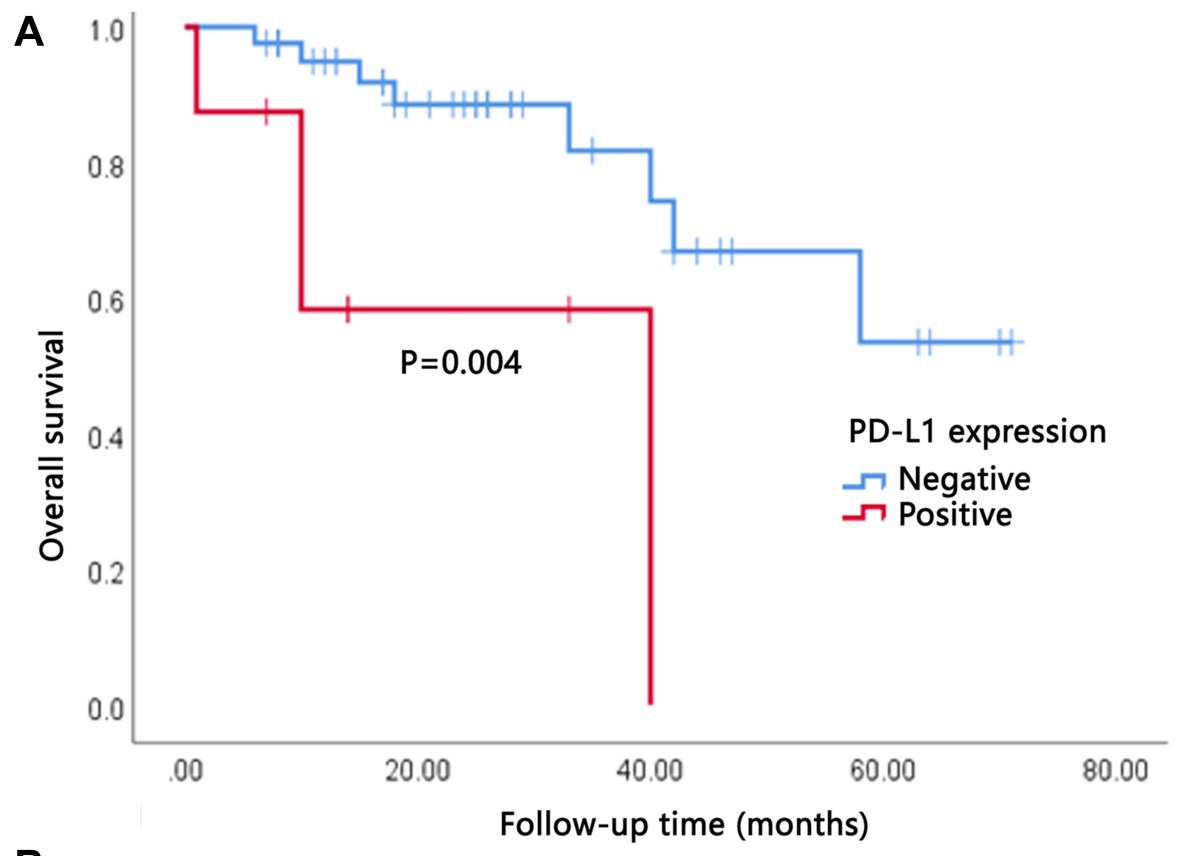

B

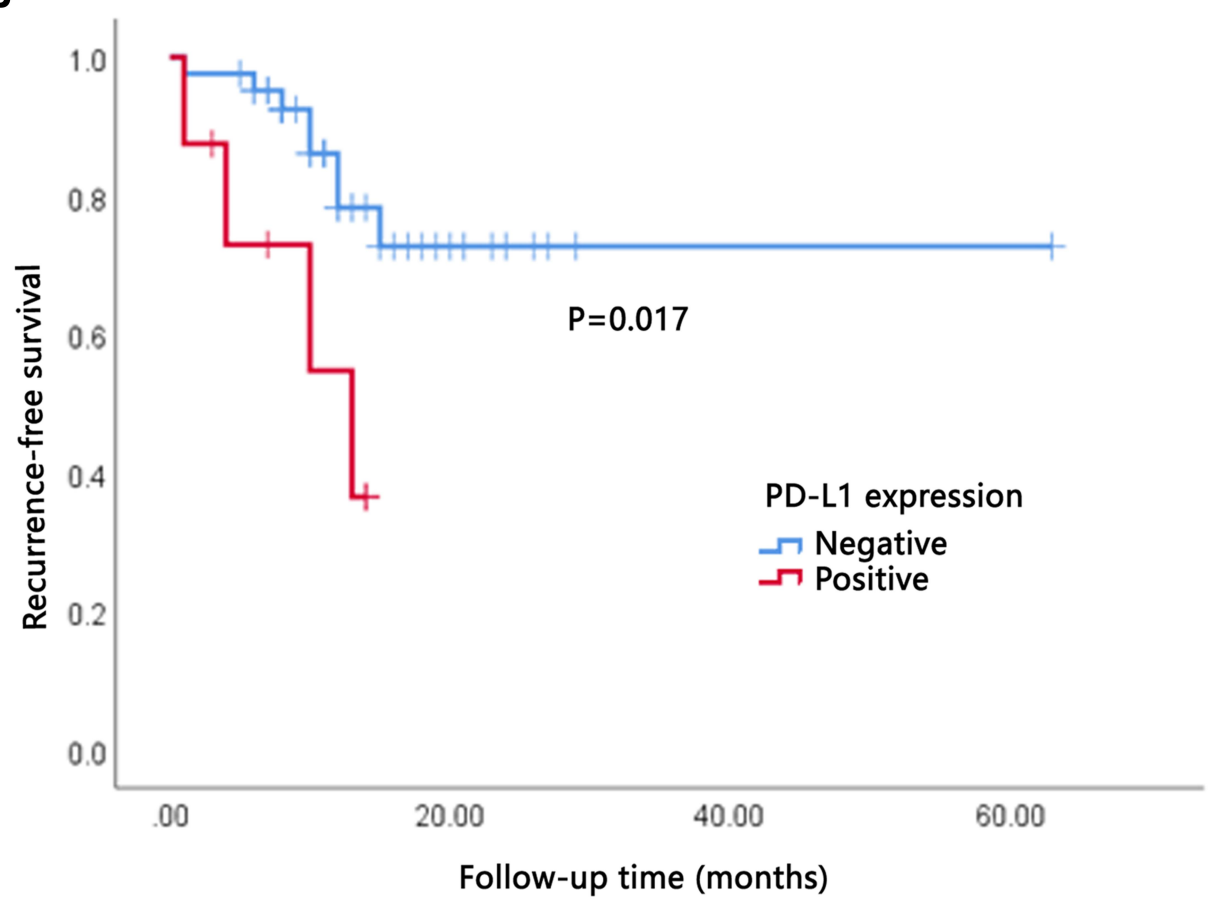

Figure 5 High degree of PD-LI expression indicated poor overall survival (OS) and recurrence-free survival (RFS). (A) OS of patients grouped by PD-LI expression. (B) RFS of patients grouped by PD-LI expression.

an individualized immune signature, which provided better prognostic accuracy than the TNM classification system. ${ }^{25}$ Although this study provided comprehensive and specific information on various immune markers in ICC, the detection was too elaborate to be used routinely in clinical practice. Moreover, the use of tissue microarray may cause sampling error.
PD-L1 is expressed in a variety of malignancies and plays a critical role in immune escape. ${ }^{26}$ Blocking PD-L1 expression to restore $\mathrm{T}$ cell function has led to durable clinical activity and safety in diverse malignancies and is promising for ICC therapy. ${ }^{27}$ PD-L1 is reportedly expressed by $17.7 \%-30.9 \%$ of ICC cases. ${ }^{16,17,28,29}$ In the present ICC cases, the PD-L1 positive rate was $16 \%$. We 
hypothesized that the highly heterogeneous positive rate may be due to the different anti-PD-L1 clones and varying cut-offs used in the studies. The biological and prognostic roles of PD-L1 in ICC were still controversial. The expression of PD-L1 in ICC was reportedly associated with a poor or a better prognosis, it is also possible that it has no association with the prognosis. ${ }^{15,30-32}$ In the present ICC cases, the PD-L1 expression was associated with a shorter OS and RFS. We also tested PD-L1 expression in relation to IS. No association was found between IS and PD-L1 expression, which was in contrast with the findings of previous studies on gastric cancer and hepatocellular carcinoma. $^{9,33}$ The upregulation of PD-L1 may promote the invasion and migration of ICC cells and exert a negative feedback inhibitory effect on AKT signaling. ${ }^{14}$ PD-L1 cell-intrinsic signaling could protect cancer cells from interferon (IFN) cytotoxicity and accelerates tumor progression. ${ }^{34}$ The expression and biologic mechanisms of the PD-L1 in ICC need to be further explored and elucidated.

A few limitations should be noted in this study. First, the prognostic model was established based on data from a single geographical area. Second, the number of patients was relatively small. Third, the comparisons between this IS system and other score systems that contained other TILs in patients with ICC needed to be further investigated.

To conclude, our results highlighted the extent of heterogeneity of ICC with respect to IS and PD-L1 expression. They both reflected some features of tumor cell biology and underlined the prognostic significance of cytotoxic inflammation in ICC. The use of IS together with PD-L1 expression may serve as a complement to the TNM staging system for predicting the prognosis of patients with ICC.

\section{Conclusion}

The IS and PD-L1 may be used as a complement to the TNM system for predicting the prognosis of patients with ICC.

\section{Disclosure}

The authors report no conflicts of interest in this work.

\section{References}

1. Chinchilla-Lopez P, Aguilar-Olivos NE, Garcia-Gomez J, et al. Prevalence, risk factors, and survival of patients with intrahepatic cholangiocarcinoma. Ann Hepatol. 2017;16(4):565-568. doi:10.5604/ 01.3001 .0010 .0293
2. Rizvi S, Khan SA, Hallemeier CL, Kelley RK, Gores GJ. Cholangiocarcinoma - evolving concepts and therapeutic strategies. Nat Rev Clin Oncol. 2018;15(2):95-111. doi:10.1038/nrclinonc. 2017.157

3. Bridgewater J, Galle PR, Khan SA, et al. Guidelines for the diagnosis and management of intrahepatic cholangiocarcinoma. $J$ Hepatol. 2014;60(6):1268-1289. doi:10.1016/j.jhep.2014.01.021

4. Gao Q, Qiu SJ, Fan J, et al. Intratumoral balance of regulatory and cytotoxic T cells is associated with prognosis of hepatocellular carcinoma after resection. J Clin Oncol. 2007;25(18):2586-2593. doi:10.1200/JCO.2006.09.4565

5. Asahi Y, Hatanaka KC, Hatanaka Y, et al. Prognostic impact of CD8+ $\mathrm{T}$ cell distribution and its association with the HLA class I expression in intrahepatic cholangiocarcinoma. Surg Today. 2020;50 (8):931-940. doi:10.1007/s00595-020-01967-y

6. Galon J, Mlecnik B, Bindea G, et al. Towards the introduction of the 'Immunoscore' in the classification of malignant tumours. $J$ Pathol. 2014;232(2):199-209. doi:10.1002/path.4287

7. Tahkola K, Mecklin JP, Wirta EV, et al. High immune cell score predicts improved survival in pancreatic cancer. Virchows Arch. 2018;472(4):653-665. doi:10.1007/s00428-018-2297-1

8. Galon J, Costes A, Sanchez-Cabo F, et al. Type, density, and location of immune cells within human colorectal tumors predict clinical outcome. Science. 2006;313(5795):1960-1964. doi:10.1126/ science. 1129139

9. Gabrielson $\mathrm{A}, \mathrm{Wu} \mathrm{Y}$, Wang $\mathrm{H}$, et al. Intratumoral $\mathrm{CD} 3$ and $\mathrm{CD} 8$ T-cell densities associated with relapse-free survival in HCC. Cancer Immunol Res. 2016;4(5):419-430. doi:10.1158/2326-6066.CIR-150110

10. Anitei MG, Zeitoun G, Mlecnik B, et al. Prognostic and predictive values of the immunoscore in patients with rectal cancer. Clin Cancer Res. 2014;20(7):1891-1899. doi:10.1158/1078-0432.CCR-13-2830

11. Chen S, Crabill GA, Pritchard TS, et al. Mechanisms regulating PD-L1 expression on tumor and immune cells. J Immunother Cancer. 2019;7(1):305. doi:10.1186/s40425-019-0770-2

12. Han X, Gu YK, Li SL, et al. Pre-treatment serum levels of soluble programmed cell death-ligand 1 predict prognosis in patients with hepatitis B-related hepatocellular carcinoma. J Cancer Res Clin Oncol. 2019;145(2):303-312. doi:10.1007/s00432-018-2758-6

13. Wu Y, Zhao T, Jia Z, et al. Polymorphism of the programmed death-ligand 1 gene is associated with its protein expression and prognosis in gastric cancer. J Gastroenterol Hepatol. 2019;34 (7):1201-1207. doi:10.1111/jgh.14520

14. Dong Z, Liao B, Shen W, Sui C, Yang J. Expression of programmed death ligand 1 is associated with the prognosis of intrahepatic cholangiocarcinoma. Dig Dis Sci. 2020;65(2):480-488. doi:10.1007/ s10620-019-05787-0

15. Zhu Y, Wang XY, Zhang Y, et al. Programmed death ligand 1 expression in human intrahepatic cholangiocarcinoma and its association with prognosis and CD8(+) T-cell immune responses. Cancer Manag Res. 2018;10:4113-4123. doi:10.2147/CMAR.S172719

16. Kriegsmann M, Roessler S, Kriegsmann K, et al. Programmed cell death ligand 1 (PD-L1, CD274) in cholangiocarcinoma - correlation with clinicopathological data and comparison of antibodies. BMC Cancer. 2019;19(1):72. doi:10.1186/s12885-018-5254-0

17. Sabbatino F, Villani V, Yearley JH, et al. PD-L1 and HLA class I antigen expression and clinical course of the disease in intrahepatic cholangiocarcinoma. Clin Cancer Res. 2016;22(2):470-478. doi:10.1158/1078-0432.CCR-15-0715

18. Maley CC, Koelble K, Natrajan R, Aktipis A, Yuan Y. An ecological measure of immune-cancer colocalization as a prognostic factor for breast cancer. Breast Cancer Res. 2015;17(1):131. doi:10.1186/ s13058-015-0638-4

19. Zeng D, Zhou R, Yu Y, et al. Gene expression profiles for a prognostic immunoscore in gastric cancer. Br J Surg. 2018;105 (10):1338-1348. doi:10.1002/bjs.10871 
20. Al-Rajhi N, Soudy H, Ahmed SA, et al. CD3+T-lymphocyte infiltration is an independent prognostic factor for advanced nasopharyngeal carcinoma. BMC Cancer. 2020;20(1):240. doi:10.1186/s12885-02006757-w

21. Peng J, Wang $Y$, Zhang $R$, et al. Immune cell infiltration in the microenvironment of liver oligometastasis from colorectal cancer: intratumoural $\mathrm{CD} 8 / \mathrm{CD} 3$ ratio is a valuable prognostic index for patients undergoing liver metastasectomy. Cancers. 2019;11 (12):1922. doi:10.3390/cancers 11121922

22. Goeppert B, Frauenschuh L, Zucknick M, et al. Prognostic impact of tumour-infiltrating immune cells on biliary tract cancer. Br J Cancer. 2013;109(10):2665-2674. doi:10.1038/bjc.2013.610

23. Naito Y, Saito K, Shiiba K, et al. CD8+ T cells infiltrated within cancer cell nests as a prognostic factor in human colorectal cancer Cancer Res. 1998;58(16):3491-3494.

24. Matsumoto $\mathrm{H}$, Thike AA, Li $\mathrm{H}$, et al. Increased CD4 and CD8-positive $\mathrm{T}$ cell infiltrate signifies good prognosis in a subset of triple-negative breast cancer. Breast Cancer Res Treat. 2016;156 (2):237-247. doi:10.1007/s10549-016-3743-x

25. Tian M, Liu W, Tao C, et al. Prediction of overall survival in resectable intrahepatic cholangiocarcinoma: ISICC -applied prediction model. Cancer Sci. 2020;111(4):1084-1092. doi:10.1111/ cas. 14315

26. Wu Y, Chen W, Xu ZP, Gu W. PD-L1 distribution and perspective for cancer immunotherapy-blockade, knockdown, or inhibition. Front Immunol. 2019;10:2022. doi:10.3389/fimmu.2019.02022

27. Banales JM, Marin JJG, Lamarca A, et al. Cholangiocarcinoma 2020: the next horizon in mechanisms and management. Nat Rev Gastroenterol Hepatol. 2020;17(9):557-588. doi:10.1038/s41575020-0310-z
28. Fontugne J, Augustin J, Pujals A, et al. PD-L1 expression in perihilar and intrahepatic cholangiocarcinoma. Oncotarget. 2017;8(15):24644-24651. doi:10.18632/oncotarget.15602

29. $\mathrm{Xu} \mathrm{G}$, Sun L, Li Y, et al. The clinicopathological and prognostic value of PD-L1 expression in cholangiocarcinoma: a meta-analysis. Front Oncol. 2019;9:897. doi:10.3389/fonc.2019.00897

30. Lu JC, Zeng HY, Sun QM, et al. Distinct PD-L1/PD1 profiles and clinical implications in intrahepatic cholangiocarcinoma patients with different risk factors. Theranostics. 2019;9(16):4678-4687. doi:10. $7150 /$ thno.36276

31. Zhao X, Guo F, Li Z, et al. Aberrant expression of B7-H4 correlates with poor prognosis and suppresses tumor-infiltration of CD8+ T lymphocytes in human cholangiocarcinoma. Oncol Rep. 2016;36 (1):419-427. doi:10.3892/or.2016.4807

32. Jing CY, Fu YP, Yi Y, et al. HHLA2 in intrahepatic cholangiocarcinoma: an immune checkpoint with prognostic significance and wider expression compared with PD-L1. J Immunother Cancer. 2019;7 (1):77. doi:10.1186/s40425-019-0554-8

33. Wen T, Wang Z, Li Y, et al. A four-factor immunoscore system that predicts clinical outcome for stage II/III gastric cancer. Cancer Immunol Res. 2017;5(7):524-534. doi:10.1158/2326-6066.CIR-160381

34. Gato-Canas M, Zuazo M, Arasanz H, et al. PDL1 signals through conserved sequence motifs to overcome interferon-mediated cytotoxicity. Cell Rep. 2017;20(8):1818-1829. doi:10.1016/j. celrep.2017.07.075
OncoTargets and Therapy

\section{Publish your work in this journal}

OncoTargets and Therapy is an international, peer-reviewed, open access journal focusing on the pathological basis of all cancers, potential targets for therapy and treatment protocols employed to improve the management of cancer patients. The journal also focuses on the impact of management programs and new therapeutic

\section{Dovepress}

agents and protocols on patient perspectives such as quality of life, adherence and satisfaction. The manuscript management system is completely online and includes a very quick and fair peer-review system, which is all easy to use. Visit http://www.dovepress.com/ testimonials.php to read real quotes from published authors. 